\title{
Early diagnosis of osteoporosis by means of orthopantomograms and oral x-rays: A systematic review
}

\author{
José López-López ${ }^{1}$, Albert Estrugo-Devesa ${ }^{2}$, Enric Jane-Salas ${ }^{1}$, Raúl Ayuso-Montero ${ }^{3}$, Carmen Gómez- \\ Vaquero $^{4}$ \\ ${ }^{1}$ Doctor of Medicine and Surgery. Professor of Oral Medicine at the School of Dentistry, University of Barcelona \\ ${ }^{2}$ Bachelor's Degree in Medicine and Surgery. Professor of Oral Medicine at the School of Dentistry, University of Barcelona \\ ${ }^{3}$ Doctor of Dentistry. Professor of Prosthetic Dentistry at the School of Dentistry, University of Barcelona \\ ${ }^{4}$ Doctor of Medicine and Surgery. Adjunct Doctor of Rheumatology at Bellvitge University Hospital
}

Correspondence:

Bellvitge University Campus

Department of Odontostomatology

Pabellón de Gobierno $2^{a}$ Planta

C/ Feixa Llarga $s / n$

08907 L'Hospitalet de Llobregat, Barcelona (Spain)

18575jll@gmail.com

Received: $14 / 09 / 2010$

Accepted: 05/01/2011
López-López J, Estrugo-Devesa A, Jane-Salas E, Ayuso-Montero R, Gómez-Vaquero C. Early diagnosis of osteoporosis by means of orthopantomograms and oral x-rays: A systematic review. Med Oral Patol Oral Cir Bucal. 2011 Nov 1;16 (7):e905-13.

http://www.medicinaoral.com/medoralfree01/v16i7/medoralv16i7p905.pdf

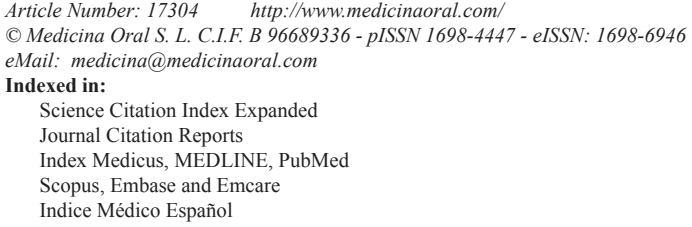

\begin{abstract}
Osteoporosis is a systemic bone disease that is characterized by a generalized reduction of the bone mass. It is the main cause of fractures in elderly women. Bone densitometry is used in the lumbar spine and hip in order to detect osteoporosis in its early stages. Different studies have observed a correlation between the bone mineral density of the jaw (BMD) and that of the lumbar spine and/or hip. On the other hand, there are studies that evaluate the findings in the orthopantomograms and perapical X-rays, correlating them with the early diagnosis of osteoporosis and highlighting the role of the dentist in the early diagnosis of this disease.

Materials and methods: A search was carried out in the Medline-Pubmed database in order to identify those articles that deal with the association between the X-ray findings observed in the orthopantomograms and the diagnosis of the osteoporosis, as well as those that deal with the bone mineral density of the jaw.

Results: There were 406 articles, and with the limits established, this number was reduced to 21 . Almost all of the articles indicate that when examining oral X-rays, it is possible to detect signs indicative of osteoporosis.

Discussion: The radiomorphometric indices use measurements in orthopantomograms and evaluate possible loss of bone mineral density. They can be analyzed alone or along with the visual indices. In the periapical X-rays, the photodensimetric analyses and the trabecular pattern appear to be the most useful. There are seven studies that analyze the densitometry of the jaw, but only three do so independently of the photodensitometric analysis.

Conclusions: The combination of mandibular indices, along with surveys on the risk of fracture, can be useful as indicators of early diagnosis of osteoporosis. Visual and morphometric indices appear to be especially important in the orthopantomograms. Photodensitometry indices and the trabecular pattern are used in periapical X-rays. Studies on mandibular dual-energy X-ray absorptiometry are inconclusive.
\end{abstract}

Key words: Dual-energy X-ray absorptiometry, mandibula index, mandibular cortical index, mandibular bone mineral density, osteoporosis. 


\section{Introduction}

Osteoporosis is a systemic bone disease that is characterized by a generalized decrease of the bone mass and a deterioration of the bone microarchitecture. It is estimated that 75 million people in Europe, Japan and the United States may be affected. It is the most significant health problem for middle-aged women, coinciding with menopause. Although changes in the bone mass and calcium metabolism are evident in the premenopausal period, menopause marks the beginning of a bone loss that continues until the end of life and is the main cause of osteoporotic fractures in elderly women (1). Aside from the hormonal risk factors, there are other risk factors for osteoporosis, particularly: family history, insufficient calcium intake, lack of moderate physical exercise, toxic habits such as smoking and excessive consumption of alcohol or of medications, especially glucocorticoids (1). As a consequence of osteoporosis, pathological fractures occur, which is a serious health and economic problem; hence the importance of early diagnosis of this pathology $(2,3)$.

In order to diagnose osteoporosis in its early phases, bone densitometry is used. This technique has become very common in the field of primary care and preventive medicine. The bone mineral density (BMD) is obtained using dual energy X-ray absorptiometry in two standard places: the hip and the lumbar spine (L2, L3 and L4). The region of the forearm can also be used. The diagnosis of osteoporosis is made according to the criteria of the $\mathrm{WHO}$ when a BMD $>2.5$ standard deviations of the young healthy population is detected (t-score $<$ $-2.5)$, considering it to be osteopenia when the BMD is between 1 and 2.5 standard deviations ( $\mathrm{t}$-score between -1 and -2.5$)(1,3)$. There are some current studies that have observed that the BMD of the mandible correlates with that obtained in the standard areas of study $(4,5)$. In the classic form, there are studies that analyze the Xray findings in the orthopantomograms (OPGs) and perapical X-rays, correlating them with the early diagnosis of osteoporosis, highlighting the important role that the dentist plays in the early diagnosis of this disease (6-8). The role of the dentist becomes even more important when we keep in mind that the OPG is a routine test that is currently performed in dental practices. These studies are usually based on the relationship between osteoporosis and the resorption of the crest of the mandibular residual ridge, resorption that is also associated with the loss of periodontal bone and with the loss of teeth (9).

The objective of this study is to review the different mandibular indices associated with osteoporosis that have been used in the literature, to evaluate whether there is scientific evidence of its possible predictive value and to evaluate the current data on studies of bone density in the mandible.

\section{Materials and Methods}

-Search Strategy

We performed a search in the Medline-Pubmed database in order to identify articles that evaluate the association between the X-ray results found in the orthopantomograms (OPMs) and intraoral X-rays and the diagnosis of osteoporosis, as well as articles that evaluate the bone mineral density of the mandible. The following keywords were used in conducting the search: 1) Mandibular bone mineral density AND osteoporosis; 2) Panoramic mandibular index and 3) Mandibular densitometric. The articles found were processed using the REFWORDS bibliographic management database.

With the search criteria 1 and 2, the following parameters were established: -a) Articles written from the year 2005 until April 2010; b) Articles written in English or in Spanish; c) Studies conducted on humans; d) Studies conducted on women. For criteria 3 (mandibular densitometric), given that there are very few articles, the results were not limited.

Of all of the articles selected, the summary was revised in order to exclude the articles that do not pertain to what is of interest in this study. Those that did not allow access to the complete text and studies that were carried out on less than 35 patients were also excluded. Some articles that were older, but of special relevance, were also included.

\section{Results}

Initially, 406 articles were found to be relevant to the subject of this study: 265 articles from the first search, 104 articles from the second search, and 40 articles from the third search. After the selection and establishment of initial limits, they were reduced to 155 articles, and finally, after their preliminary evaluation, they were reduced to 21 articles, which were then analyzed in depth (Table 1, Table 2).

We found 10 articles that use radiomorphometric indices for comparing the results obtained with these measurements and those obtained by dual energy Xray absorption scans for diagnosing osteoporosis. They use the following indices: MCT (Mandibular Cortical Thickness) $(4,6,7)$, or for other authors, MCW (Mandibular Cortical Width) (8); both mean measurements of the thickness of the mandibular inferior cortical bone. The thickness of the mandibular cortical bone is measured on both sides of the jaw. A line is traced that passes through the center of the mentonian foramen and tangent to a line traced in the lower edge of the mandible. The thickness of the inferior cortical bone is measured on this line. The PMI (Panoramic Mandibular Index) (4, 7) is the ratio between the thickness of the mandibular cortical bone and the distance between the mentonian foramen and the mandibular inferior cortical bone. Using the same line described above, measurements are 
Table 1. Summary of the studies reviewed and the strategies of elimination used.

\begin{tabular}{|l|c|c|c|c|c|}
\hline & $\begin{array}{c}\text { Total } \\
\text { articles }\end{array}$ & $\begin{array}{c}\text { Language and Humans, } \\
\text { 2005-2010 }\end{array}$ & $\begin{array}{c}\text { Elimination of } \\
\text { duplicates }\end{array}$ & Unrelated & Final \\
\hline $\begin{array}{l}\text { Mandibular bone mineral } \\
\text { density AND osteoporosis }\end{array}$ & 265 & 105 & 69 & 19 & 6 \\
\hline $\begin{array}{l}\text { Panoramic mandibular } \\
\text { index }\end{array}$ & 104 & 46 & 46 & 19 & 8 \\
\hline Mandibular densitometric & 40 & 40 & 40 & 13 & 7 \\
\hline TOTAL & 409 & 191 & 155 & 51 & $\mathbf{2 1}$ \\
\hline
\end{tabular}

taken between the upper edge of the mandible and the upper and lower edge of the mentonian foramen. The average of the two values is then calculated. Using these measurements and that of the thickness of the cortical bone, the PMI for the upper and lower margin of the mentonian foramen is calculated on both sides, and then the average is calculated (Fig. 1).

We found 4 studies that only use the visual estimate of the inferior cortical of the edge of the mandible. These indices do not need measurements, but are only based on the observation of the quality of the cortical bone. The appearance of the inferior cortical edge of the mandible in the region posterior to the mentonian foramen was classified by Klemetti et al. (9) in three categories: $\mathrm{C} 1, \mathrm{C} 2$ and $\mathrm{C} 3$, according to its degree of resorption (Fig. 2).

Seven articles were selected, which use the photodensitometric analyses and analyses of trabecular patterns in the panoramic and intraoral X-rays. In order to make the photodensitometric analyses, according to the authors, a graduated scale of aluminum is used with different degrees of density, in order to compare it with the X-ray and to thus obtain a measurement of the gray scale. The scale of aluminum is used in research studies on densitometry because the absorption and dispersion properties of the aluminum are similar to those of the bone. In addition, using the same scale in the digital $\mathrm{X}$-rays and through a computer program, by knowing the thickness of the scale and intensity of the pixels, it is possible to obtain a densitometric reference of the area to be studied.

The optical densitometry is obtained by analyzing the $\mathrm{X}$-rays shown and processed. The optical density is analyzed with a densitometer, with an approximate opening of $2 \mathrm{~mm}$, obtaining the average of the optical density in the alveolar bone in 5 places (3 throughout each side of the root of the first premolar and 2 between the two inferior premolars, $6 \mathrm{~mm}$ apical of the estimate of the amelocementary joint in the patient).
Measurements of the trabeculation can be obtained in periapical X-rays using three X-rays of the right premolar area, classifying it according to the classification by Lindh et al. (10): 1) sparse trabeculation, 2) alternating dense and sparse trabeculation, 3) dense trabeculation. Only three articles use the densitometric measurements of the mandible and compare them with the standard places of study in the lumbar spine, hip and forearm (5-7).

\section{Discussion}

Although osteoporosis affects both men and women, the female population is the most affected by osteoporosis, which is why it is common to find articles in which only women are the subject of study.

-Radiomorphometric indices. These indices use measurements made in the orthopantomograms, which can evaluate bone loss that can presuppose a possible loss of bone mineral density. In 1998, Horner and Devlin (5) used MCT and PMI in analog X-rays and found a positive relationship between the reduction of these indices and the decrease of bone density. In 2002, the same authors, Devlin and Horner (7), used measurements of the thickness of the mandibular cortical bone in the area of the foramen (MI), in the area of the angle (gonial index, GI) and in the antegonial area (AI), finding significant results only for the MI. In 2004, White et al. (11) used MCT and visual exams of the cortical bone described according to Klemetti et al. (9) and find positive results for both. In 2006, Arifin et al. (12) used a computer-assisted method in digital X-rays for determining the MTC, considering it suitable for diagnosing the patients' BMD. In 2006, Taguchi et al. (13) used MCT, a visual estimate (Klemetti et al.) (9) and the OST index (osteoporosis self-assessment tool) — which is a survey of risk factors (10) — in 158 patients, concluding that dentists are able to refer women who are under the age of 65 years old so that a bone densitometry is performed only with the findings of the panoramic X-rays. In 2007, this same author (14) used the thickness of the 


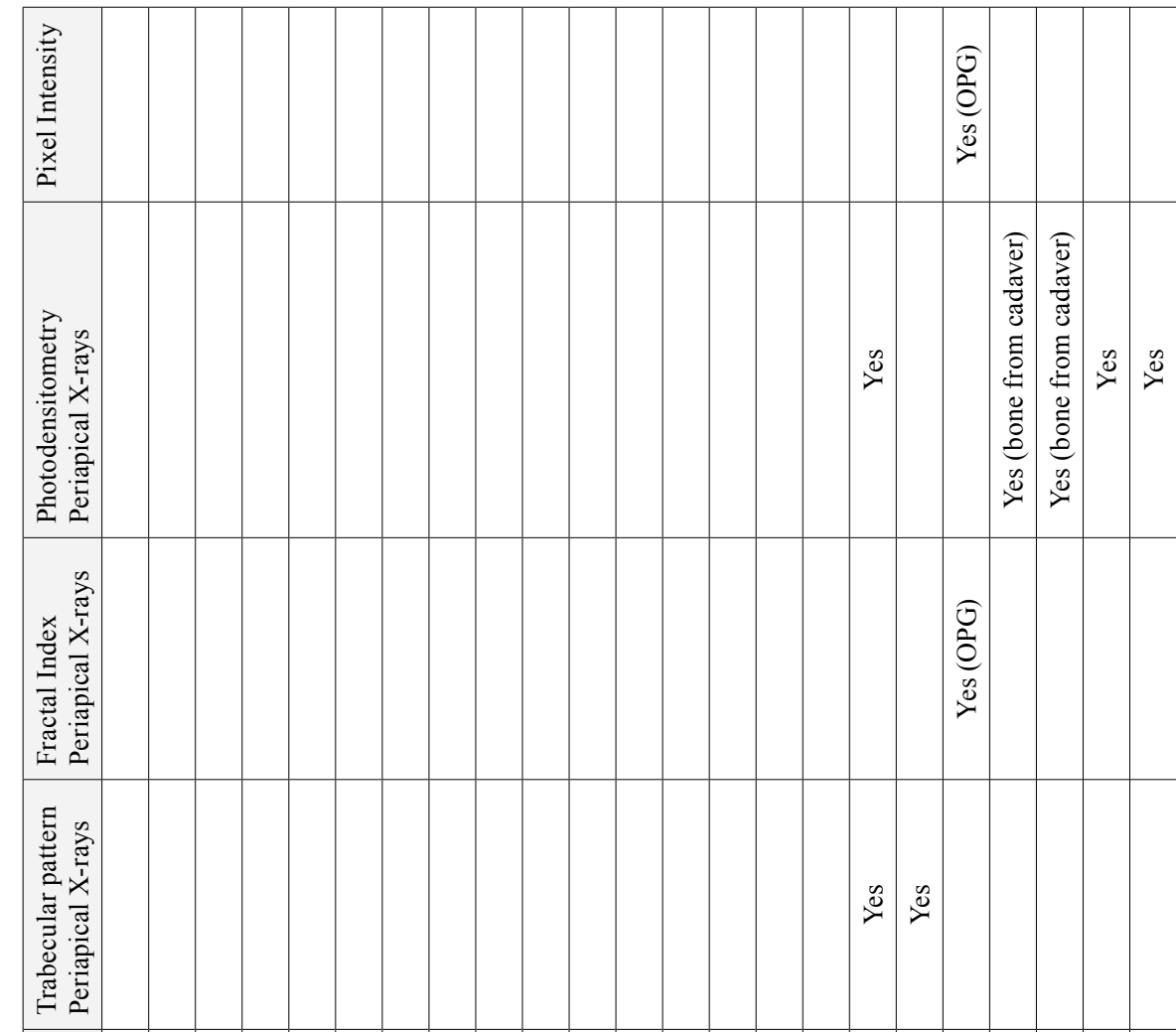

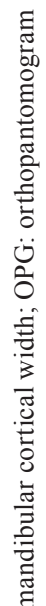

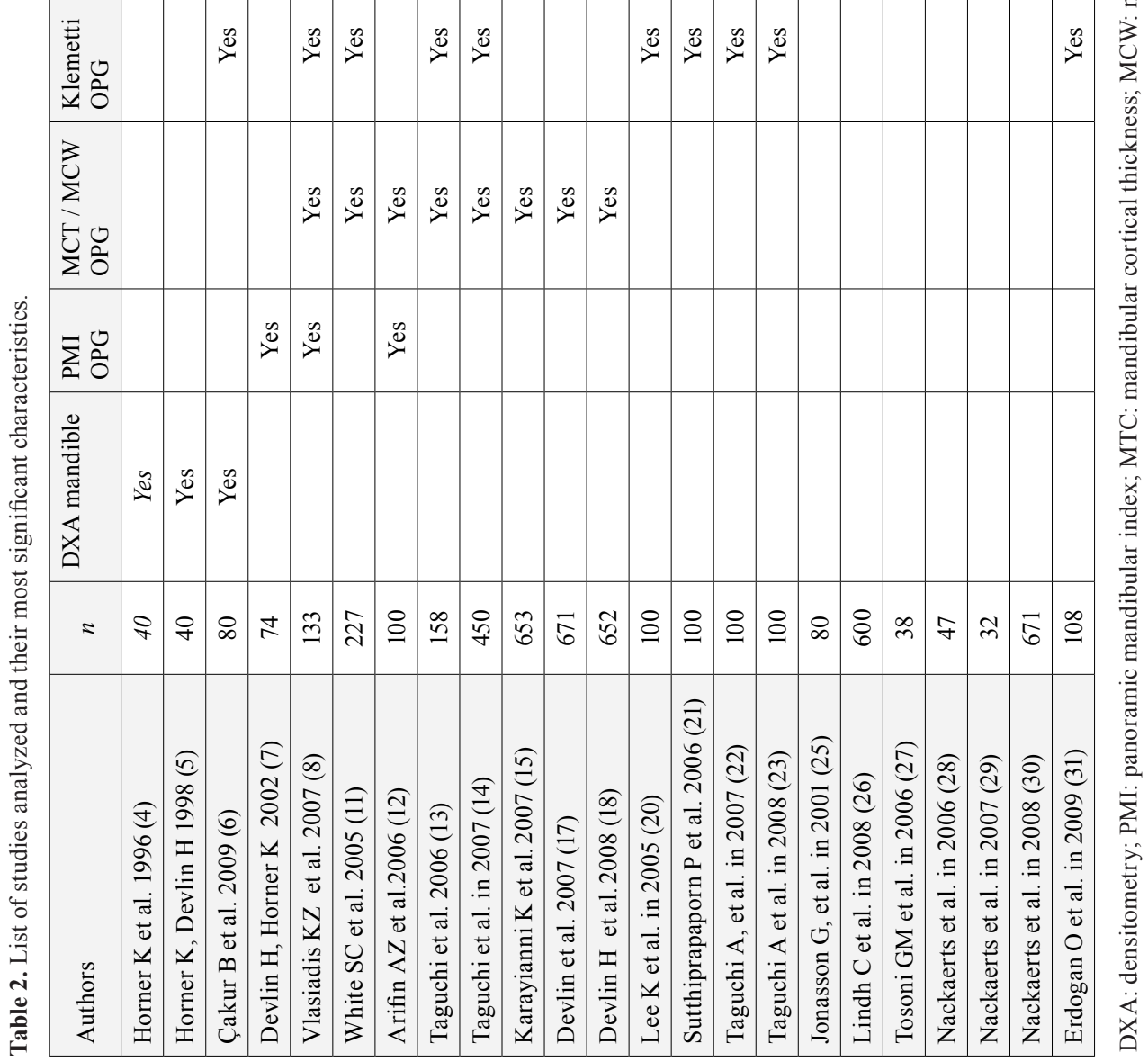




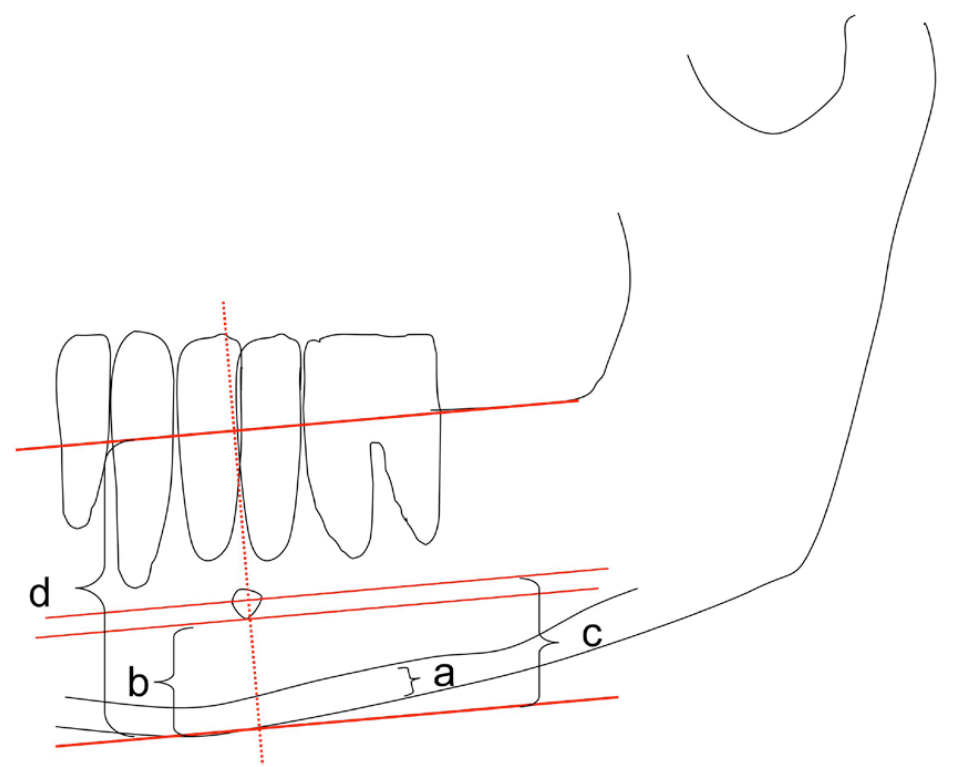

Fig. 1. Different measurements can be estimated manually in the panoramic Xrays. These measurements are defined as: thickness of the mandibular cortical bone (mandibular cortical width: $\mathrm{MCW}$ ): a, panoramic mandibular index (PMI): $\mathrm{a} / \mathrm{b}$, alveolar resorption index (mandibular alveolar bone resorption index: $\mathrm{MM}$ ratio): $\mathrm{d} / \mathrm{c}$. All of these measurements are made in millimeters. If the mentonian foramen is visible on both sides, the average is taken.
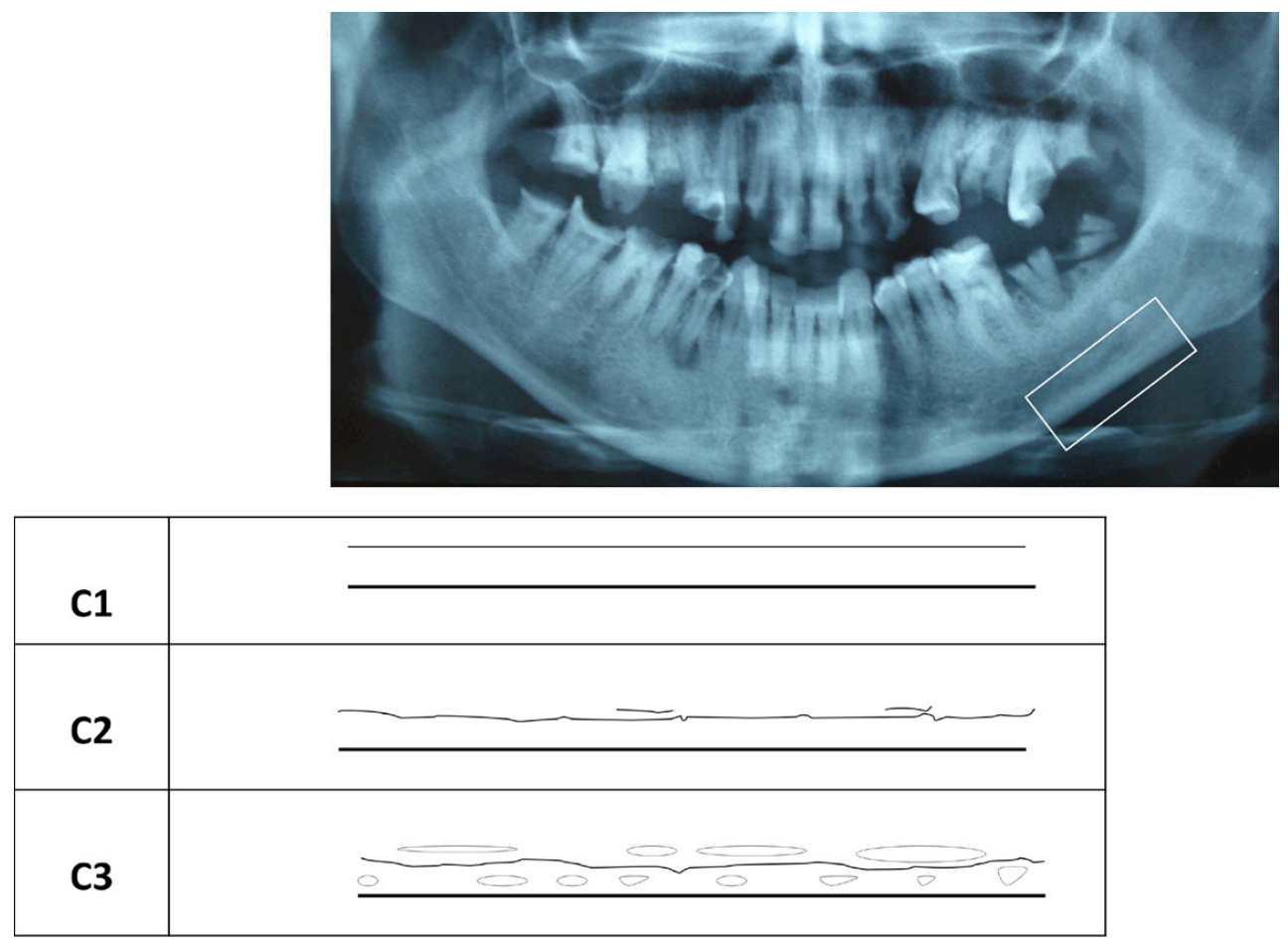

Fig. 2. Values of the visual estimate of the cortical bone, according to Klemetti (9). C1: The endostic margin is uniform and marked on both sides. C2: Slightly or moderately eroded. The endostic margin appears to have semilunar defects (lacunar resorption) or there appear to be forms of cortical residues. C3: Cortex severely eroded. The cortical bone is clearly porous and there is a significant amount of residue. 
cortical bone and the visual estimate in 450 patients, finding that there is an increase in the risk of low bone mineral density or osteoporosis for post-menopausal women with alterations of the mandible. In 2007, Vlasiadis et al. (8) used data obtained with the PMI, MCT indices, degree of resorption of the crest (M/M ratio, that is another index that is used as support), morphological classification of the inferior cortex (MCI or Klemetti index) and number of teeth lost, in order to validate the radiomorphometric measurements, to determine the bone resorption in different groups of women and to diagnose osteoporosis. They find that when the lumbar spine T-score decreases, the MTC decreases significantly and that this index plus the number of teeth lost have a statistically significant effect on the incidence of moderate or severe erosion of the mandibular cortex. They conclude that dentists have sufficient X-ray information in order to do a screening for osteoporosis. In 2007, Karayianni et al. (15) compare clinical surveys and X-ray findings in order to identify the risk for development of osteoporosis in women. This study is part of the OSTEODENT project, which began in 2003, consisting of the collaboration of European centers for research of the role of dental X-rays in the diagnosis of osteoporosis. The main goal of this project is to identify the most useful and effective X-ray index or combination of clinical and X-ray indices used by dentists for diagnosing osteoporosis. In this article, the measurements of the MCT in the X-rays are combined with the survey for calculating the rate of risk of osteoporosis OSIRIS (16) (Osteoporosis Index Risk) for estimating the risk of low bone mineral density. It is calculated based on four variables: age, weight, use of hormonal replacement therapy and a history of trauma from moderate contusions (Table 3). It concludes that OSIRIS has more diagnostic validity than the measurements of the cortical bone in the X-rays, which is why it does not recommend performing X-rays in order to detect the risk of osteoporosis, due to the additional risk of exposure to radiation. However, these measurements are an alternative for evaluating the risk in patients who have undergone an X-ray exam for other purposes. In addition, in the OSTEODENT project, in 2007, Devlin et al. (17) used the measurements of the mandibular cortical thickness (MCT) and visual assessment of the cortical bone, concluding that patients who obtained measurements of the cortical thickness $<3 \mathrm{~mm}$ must be referred for subsequent studies to determine whether or not there is a presence of osteoporosis. As part of the OSTEODENT project, in 2008, Devlin et al. (18) used an automatic system in panoramic X-rays in order to detect the thickness of the cortical bone, as described by Allen et al. (19), combined with the OSIRIS rates of risk, concluding that dentists play an essential role in the initial detection of patients with a high risk factor for developing osteoporosis.

-Visual indices. Apart from the articles mentioned previously, which combine these visual findings with the radiomorphometric indices, we found four studies that use only visual estimates for identifying low bone mineral density (BMD). In 2005, Lee et al. (20) used the reports of three radiologists and a dentist for analyzing the mandibular inferior cortex in the X-rays and for observing whether or not it was thin. They also made measurements of the thickness of the cortical bone. In 2006, Sutthiprapaporn et al. (21) used the collaboration of 111 general dentists in order to classify $100 \mathrm{X}$-rays of post-menopausal women who had undergone a study of their bone mineral density by densitometry, according to the classification by Klemetti on patients with a normal or eroded cortex (Fig. 2). In 2007, Taguchi et al. (22) conducted a study in which an experienced radiologist trained 22 general dentists on the observation of erosion of the mandibular inferior cortex in 100 panoramic X-rays of women who

Table 3. OSIRIS Index (Osteoporosis Index Risk) (16) for estimating the risk of low Bone Mineral Density According to the total of the values of the variables, the risk of having low Bone Mineral Density is determined to be high, medium or low.

\begin{tabular}{|l|l|}
\hline Age & $-0.2 \times$ Age \\
\hline Weight in kilograms & $0.2 \times$ Weight \\
\hline Use of hormone replacement therapy & 0.2 \\
\hline $\begin{array}{l}\text { History of trauma from moderate contu- } \\
\text { sions }\end{array}$ & -0.2 \\
\hline TOTAL OF ALL OF THE VARIABLES & $\mathrm{X}$ \\
\hline \multicolumn{2}{|l}{} \\
\hline OSIRIS & RISK OF LOW BMD \\
\hline $\mathrm{X}<-3$ & HIGH \\
\hline $\mathrm{X}<+1>-3$ & MEDIUM \\
\hline $\mathrm{X}>+1$ & LOW \\
\hline & \\
\hline
\end{tabular}


had previously been classified by DXA into three groups: normal, osteopenic and osteoporotic. In 2008, with the aim of demonstrating that general dentists are able to identify women with osteoporosis, the same authors (23) created a platform (website) with instructions on how to screen for osteoporosis and on the interpretation of the erosion of the mandibular cortex into the categories: $\mathrm{C} 1$, $\mathrm{C} 2$ and $\mathrm{C} 3$. On this platform, one can find 100 digital $\mathrm{X}$-rays of post-menopausal women. All of the previous studies conclude that the analysis of erosion of the cortical bone is effective for identifying post-menopausal women who would be candidates for posterior densitometric studies in a high percentage, which Sutthiprapaporn et al. manage to calculate to be $73 \%(21,24)$.

- Photodensitometric analysis and trabecular pattern. Different studies use the photodensitometries in the periapical X-rays and the trabecular pattern that is observed in them in order to predict the bone mineral density. In 2001 (25), Jonasson et al. evaluated the trabecular pattern, the mass of alveolar bone measured by photodensitometry and the interdental alveolar thickness, in order to predict the bone mineral density of the skeleton. The interdental alveolar thickness is measured with dental calipers between the two inferior premolars, $6 \mathrm{~mm}$ apical of the amelocementary joint in the patient. The mass of the alveolar bone is measured in periapical X-rays of the premolar area, adding a scale of graduated aluminum. As for the trabecular pattern, we refer to the work of Lindh et al. (26) in 2008, as part of the OSTEODENT project, in which 5 different observers are presented with different X-rays of the superior and inferior premolar region and have to classify them into three groups (dense homogeneous trabecular pattern, heterogeneous trabecular pattern and sparse homogeneous trabecular pattern) according to three reference images of each pattern. In addition, a survey of fracture risk factors was carried out. They concluded that the visual estimate of the trabecular pattern in the intraoral $\mathrm{X}$-rays of the premolar region is a potential method for identifying women at risk for osteoporosis.

Using digital radiology, we found the study by Tosoni et al. (27) in 2006, in which the pixel intensity (PI) and the fractal dimension (FD) are studied in the panoramic $\mathrm{X}$-rays, in order to evaluate their effectiveness in the detection of osteoporosis associated with densitometric changes in the bone. Three regions of interest (ROI) are selected on the left side of the orthopantomograms, in the area of the angle, body and canine/ premolar region $(\mathrm{C} / \mathrm{P})$. For the analysis of the PI, the measurements of the three ROI are taken and compared with those of some standardized scales of aluminum. For the study of the FD, the ROI of the angle and of the $\mathrm{C} / \mathrm{P}$ area are taken. Both images are transformed to 8-bits and are processed with specific software. The study concludes that osteoporotic changes can be detected in the spongy bone in the digital X-rays. In order to develop a method for densitometry of the mandible in the periapical Xrays, in 2006, Nackaerts et al. (28) used samples of the mandibular premolar region in cadavers on which they perform digital X-rays, placing a scale of aluminum for determining the gray scale. Bone mineral density tests and volumetric detections were also performed. They decalcified some samples and took X-rays that they analyzed using a computer program, calculating the degree of decalcification, and thus obtaining a method for evaluating the bone mineral density with the intraoral X-rays, comparing the decalcification with the reference of the scale of aluminum. In 2007 (29), the same group conducted a study in order to determine whether the scale of aluminum is necessary for performing optical densitometry when evaluating intraoral X-rays. In 2008 (30), as part of the OSTEODENT project, the same authors used conventional intraoral X-rays with the scale of aluminum of the superior and inferior premolar region, then digitized and analyzed the X-rays with a specific software. In this case, an analysis of the ROC (Receiver operating characteristic) curves was made and they concluded that the densitometry of the premolar region offers reasonable diagnostic precision, which could improve if additional factors are included in the analysis and perfection of the technique.

Finally, in 2009, Erdogan et al. (31) studied the relationship between that found in the oral territory and osteoporosis, among which are the visual estimates in the orthopantomograms, according to Klemetti, and the photodensitometry of the periapical X-rays. In addition to the X-ray analyses, they analyzed the number of permanent teeth, loss of support, depth of pockets and mobility of each tooth. The periapical X-rays were taken of the molar region and anterior region of the upper maxilla and the mandible, and photodensitometry was carried out using the scale of aluminum. The study arrives at the conclusion that both the X-ray findings as well as the oral exam can be predictors of osteoporosis on their own, but the combination of them in post-menopausal women is very important when it comes to diagnosing the early stages of osteoporosis. The different indices mentioned are summarized in Table 4.

-Densitometry of the mandible (DXA). Of the seven articles of this group, only three of them (Horner $\mathrm{K}$ et al. 1996 (4), Horner K, Devlin 1998 (5), Çakur B et al. 2009 (6)) use densitometry of the mandible; the rest use the photodensitometry analyses along with densitometry of the mandible. Horner et al. (4) analyzed 40 edentulous patients in order to carry out DXA in the mandible, encountering problems in the positioning of the patients. They used densitometry to compare the results in the mandible and the standard places of study, obtaining a positive relationship. They used densitometry, overlapping the contralateral sides of the jaw and taking meas- 
Table 4. Different indices analyzed, their meaning and the most relevant author.

\begin{tabular}{|c|c|c|}
\hline INDEX / MEASUREMENT & EVALUATION & AUTHOR \\
\hline $\begin{array}{l}\text {-MCT (Mandibular cortical Thickness) } \\
\text {-MCW (Mandibular cortical width) }\end{array}$ & Thickness of the mandibular inferior cortical & Horner K and Devlin H, 1998 (5) \\
\hline PMI (Panoramic mandibular index) & $\begin{array}{l}\text { Ratio between the thickness of the mandibular } \\
\text { cortical bone and the distance between the } \\
\text { mentonian foramen and the mandibular inferior } \\
\text { cortical bone }\end{array}$ & Horner K and Devlin H, 1998 (5) \\
\hline MI (Mandibula Index) & $\begin{array}{l}\text { Measures the thickness of the cortical bone in } \\
\text { the area of the mentonian foramen }\end{array}$ & Horner K and Devlin H, 1998 (5) \\
\hline GI (Gonial Index) & $\begin{array}{l}\text { Measures the thickness of the cortical bone in } \\
\text { the area of the gonial angle }\end{array}$ & Horner K and Devlin H, 1998 (5) \\
\hline AI (Antogonial Index) & $\begin{array}{l}\text { Measures the thickness of the cortical bone in } \\
\text { the area located in front of the gonial angle }\end{array}$ & Horner K and Devlin H, 1998 (5) \\
\hline Klemetti Index (MIC grade) & $\begin{array}{l}\text { Visual estimate of the inferior cortical of the } \\
\text { edge of the mandible }\end{array}$ & Klemetti E, et al., 1994 (9) \\
\hline OST Index (osteoporosis self-assessment tool) & A survey of risk factors & Lindh C., et al., 1996 (10) \\
\hline $\begin{array}{l}\text { Degree of resorption of the crest } \\
\text { (M/M ratio) }\end{array}$ & $\begin{array}{l}\text { Division between total mandibular height and } \\
\text { distance between the mentonian foramen and the } \\
\text { inferior cortical bone }\end{array}$ & Vlasiadis KZ, et al., 2007 (8) \\
\hline Photodensitometric analysis & Measurement of gray scales & Jonasson G, et al., 2001 (25) \\
\hline Trabecular pattern & $\begin{array}{l}\text { Measurements of the trabeculation in periapical } \\
\text { X-rays }\end{array}$ & Lindh C., et al., 2008 (26) \\
\hline PI (Pixel Intensity) & $\begin{array}{l}\text { Evaluation of the pixel intensity on digital X- } \\
\text { rays }\end{array}$ & Tosoni GM, et al., 2006 (27) \\
\hline FD (fractal dimension) & $\begin{array}{l}\text { Creation of fractal dimension computing for } \\
\text { evaluating osteoporotic changes in the bone }\end{array}$ & Tosoni GM, et al., 2006 (27) \\
\hline
\end{tabular}

urements of 3 regions of interest (ROI), which include the ascending ramus, body and mandibular symphysis. In the second study, they used the DXA validated in the first study to compare it with the results obtained in the orthopantomograms, in order to demonstrate that the parameters used in these for the diagnosis of osteoporosis coincides with the results obtained by DXA. Çacur et al. (6) used another position of the patients for the DXA, given that in the study by Horner et al. (5), they encountered difficulties in the positioning proposed for obtaining the overlapping of both sides of the jaw. They positioned the patients in such a way so as to obtain an image similar to that of the panoramic X-rays, in order to avoid having to make overlapping images. In their conclusions, they did not find any correlation between the bone mineral density (BMD) obtained in the densitometry of the jaw and that obtained in the hip and lumbar spine. In order to analyze the data of the BMD, they used the vertebral column software. On the other hand, Horner et al. (5) found a relationship using their position and the forearm software.

\section{Conclusions}

There is scientific evidence that the decrease in bone mass due to osteoporosis also affects the mandible, and that this loss of bone density can be proven in the routine oral exams or prior to dental treatment, both by means of orthopantomograms as well as by periapical X-rays. There are methods that require making measurements that are somewhat sophisticated (PMI, MTC, photodensitometry, etc.) and others in which a simple visual check (Klemetti, trabecular pattern) enables us to observe that there is evidence of a loss of bone mass. The visual exams tend to be a bit subjective, as they depend on the level of training of the examining doctor.

Mandibular densitometry is in a preliminary stage as far as its possible use as a reference of densitometry made in the standard areas.

The mandibular indices combined with surveys on the risk of fracture can be used for an early diagnosis of osteoporosis, and enable referring the patient to have his or her bone mineral density studied in order to make the diagnosis and subsequently treat the disease. Therefore, the dentist can play a very important role in the early diagnosis of osteoporosis and osteopenia. 


\section{References with links to Crossref - DOI}

\section{References}

1. World Health Organization. Assessment of fracture risk and its application to screening for postmenopausal osteoporosis. WHO Technical Report Series 843.Ginebra: WHO; 1994.

2. Diaz Curiel M, Carrasco de la Peña JL, Honorato Perez J, Perez Cano R, Rapado A, Ruiz Martinez I. Study of bone mineral density in lumbar spine and femoral neck in a Spanish population. Multicentre Research Project on Osteoporosis. Osteoporos Int. 1997;7:59-64. 3. Nolla JM, Gómez-Vaquero C, Fiter J, Roig Vilaseca D, Mateo L, Rozadilla A, et al. Usefulness of bone densitometry in postmenopausal women with clinically diagnosed vertebral fractures. Ann Rheum Dis. 2002;61:73-5.

4. Horner K, Devlin H, Alsop CW, Hodgkinson IM, Adams JE. Mandibular bone mineral density as a predictor of skeletal osteoporosis. Br J Radiol. 1996;69:1019-25.

5. Horner K, Devlin H. The relationship between mandibular bone mineral density and panoramic radiographic measurements. J Dent. 1998;26:337-43.

6. Cakur B, Dagistan S, Sahin A, Harorli A, Yilmaz A. Reliability of mandibular cortical index and mandibular bone mineral density in the detection of osteoporotic women. Dentomaxillofac Radiol. 2009;38:255-61.

7. Devlin H, Horner K. Mandibular radiomorphometric indices in the diagnosis of reduced skeletal bone mineral density. Osteoporos Int. 2002;13:373-8.

8. Vlasiadis KZ, Skouteris CA, Velegrakis GA, Fragouli I, Neratzoulakis JM, Damilakis J, et al. Mandibular radiomorphometric measurements as indicators of possible osteoporosis in postmenopausal women. Maturitas. 2007;58:226-35.

9. Klemetti E, Kolmakov S, Kröger H. Pantomography in assessment of the osteoporosis risk group. Scand J Dent Res. 1994;102:68-72.

10. Lindh C, Petersson A, Rohlin M. Assessment of the trabecular pattern before endosseous implant treatment: diagnostic outcome of periapical radiography in the mandible. Oral Surg Oral Med Oral Pathol Oral Radiol Endod. 1996;82:335-43.

11. White SC, Taguchi A, Kao D, Wu S, Service SK, Yoon D, et al. Clinical and panoramic predictors of femur bone mineral density. Osteoporos Int. 2005;16:339-46.

12. Arifin AZ, Asano A, Taguchi A, Nakamoto T, Ohtsuka M, Tsuda $\mathrm{M}$, et al. Computer-aided system for measuring the mandibular cortical width on dental panoramic radiographs in identifying postmenopausal women with low bone mineral density. Osteoporos Int. 2006;17:753-9.

13. Taguchi A, Tsuda M, Ohtsuka M, Kodama I, Sanada M, Nakamoto $\mathrm{T}$, et al. Use of dental panoramic radiographs in identifying younger postmenopausal women with osteoporosis. Osteoporos Int. 2006;17:387-94.

14. Taguchi A, Ohtsuka M, Tsuda M, Nakamoto T, Kodama I, Inagaki K, et al. Risk of vertebral osteoporosis in post-menopausal women with alterations of the mandible. Dentomaxillofac Radiol. 2007;36:143-8.

15. Karayianni K, Horner K, Mitsea A, Berkas L, Mastoris M, Jacobs $\mathrm{R}$, et al. Accuracy in osteoporosis diagnosis of a combination of mandibular cortical width measurement on dental panoramic radiographs and a clinical risk index (OSIRIS): the OSTEODENT project. Bone. 2007;40:223-9.

16. Sedrine WB, Chevallier T, Zegels B, Kvasz A, Micheletti MC, Gelas B, et al. Development and assessment of the Osteoporosis Index of Risk (OSIRIS) to facilitate selection of women for bone densitometry. Gynecol Endocrinol. 2002;16:245-50.

17. Devlin H, Karayianni K, Mitsea A, Jacobs R, Lindh C, van der Stelt $\mathrm{P}$, et al. Diagnosing osteoporosis by using dental panoramic radiographs: the OSTEODENT project. Oral Surg Oral Med Oral Pathol Oral Radiol Endod. 2007;104:821-8.

18. Devlin H, Allen P, Graham J, Jacobs R, Nicopoulou-Karayianni $\mathrm{K}$, Lindh $\mathrm{C}$, et al. The role of the dental surgeon in detecting osteoporosis: the OSTEODENT study. Br Dent J. 2008;204:E16.

19. Allen PD, Graham J, Farnell DJ, Harrison EJ, Jacobs R, Nico-
polou-Karayianni K, et al. Detecting reduced bone mineral density from dental radiographs using statistical shape models. IEEE Trans Inf Technol Biomed. 2007;11:601-10.

20. Lee K, Taguchi A, Ishii K, Suei Y, Fujita M, Nakamoto T, et al. Visual assessment of the mandibular cortex on panoramic radiographs to identify postmenopausal women with low bone mineral densities. Oral Surg Oral Med Oral Pathol Oral Radiol Endod. 2005;100:226-31.

21. Sutthiprapaporn P, Taguchi A, Nakamoto T, Ohtsuka M, Mallick PC, Tsuda M, et al. Diagnostic performance of general dental practitioners after lecture in identifying post-menopausal women with low bone mineral density by panoramic radiographs. Dentomaxillofac Radiol. 2006;35:249-52.

22. Taguchi A, Ohtsuka M, Nakamoto T, Naito K, Tsuda M, Kudo Y, et al. Identification of post-menopausal women at risk of osteoporosis by trained general dental practitioners using panoramic radiographs. Dentomaxillofac Radiol. 2007;36:149-54.

23. Taguchi A, Asano A, Ohtsuka M, Nakamoto T, Suei Y, Tsuda M, et al. Observer performance in diagnosing osteoporosis by dental panoramic radiographs: results from the osteoporosis screening project in dentistry (OSPD). Bone. 2008;43:209-13.

24. Taguchi A. Triage screening for osteoporosis in dental clinics using panoramic radiographs. Oral Dis. 2010;16:316-27.

25. Jonasson G, Bankvall G, Kiliaridis S. Estimation of skeletal bone mineral density by means of the trabecular pattern of the alveolar bone, its interdental thickness, and the bone mass of the mandible. Oral Surg Oral Med Oral Pathol Oral Radiol Endod. 2001;92:34652.

26. Lindh C, Horner K, Jonasson G, Olsson P, Rohlin M, Jacobs R, et al. The use of visual assessment of dental radiographs for identifying women at risk of having osteoporosis: the OSTEODENT project. Oral Surg Oral Med Oral Pathol Oral Radiol Endod. 2008;106:28593.

27. Tosoni GM, Lurie AG, Cowan AE, Burleson JA. Pixel intensity and fractal analyses: detecting osteoporosis in perimenopausal and postmenopausal women by using digital panoramic images. Oral Surg Oral Med Oral Pathol Oral Radiol Endod. 2006;102:235-41.

28. Nackaerts O, Jacobs R, Pillen M, Engelen L, Gijbels F, Devlin $\mathrm{H}$, et al. Accuracy and precision of a densitometric tool for jaw bone. Dentomaxillofac Radiol. 2006;35:244-8.

29. Nackaerts O, Jacobs R, Horner K, Zhao F, Lindh C, Karayianni $\mathrm{K}$, et al. Bone density measurements in intra-oral radiographs. Clin Oral Investig. 2007;11:225-9.

30. Nackaerts O, Jacobs R, Devlin H, Pavitt S, Bleyen E, Yan B, et al. Osteoporosis detection using intraoral densitometry. Dentomaxillofac Radiol. 2008;37:282-7.

31. Erdogan O, Incki KK, Benlidayi ME, Seydaoglu G, Kelekci S. Dental and radiographic findings as predictors of osteoporosis in postmenopausal women. Geriatr Gerontol Int. 2009;9:155-64. 